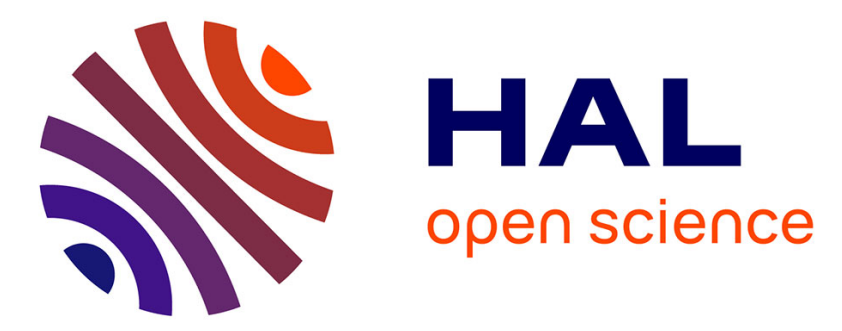

\title{
P-wave tomography of the mantle beneath the South Pacific Superswell revealed by joint ocean floor and islands broadband seismic experiments
}

\author{
S. Tanaka, M. Obayashi, D. Suetsugu, H. Shiobara, H. Sugioka, J. \\ Yoshimitsu, T. Kanazawa, Y. Fukao, Guilhem Barruol
}

\section{To cite this version:}

S. Tanaka, M. Obayashi, D. Suetsugu, H. Shiobara, H. Sugioka, et al.. P-wave tomography of the mantle beneath the South Pacific Superswell revealed by joint ocean floor and islands broadband seismic experiments. Physics of the Earth and Planetary Interiors, 2009, 172 (3-4), pp.268-277. 10.1016/j.pepi.2008.10.016 . hal-00413036

\section{HAL Id: hal-00413036 \\ https://hal.science/hal-00413036}

Submitted on 26 Oct 2016

HAL is a multi-disciplinary open access archive for the deposit and dissemination of scientific research documents, whether they are published or not. The documents may come from teaching and research institutions in France or abroad, or from public or private research centers.
L'archive ouverte pluridisciplinaire HAL, est destinée au dépôt et à la diffusion de documents scientifiques de niveau recherche, publiés ou non, émanant des établissements d'enseignement et de recherche français ou étrangers, des laboratoires publics ou privés. 


\title{
P-wave tomography of the mantle beneath the South Pacific Superswell revealed by joint ocean floor and islands broadband seismic experiments
}

\author{
S. Tanaka ${ }^{\mathrm{a}, *}$, M. Obayashi $^{\mathrm{a}}$, D. Suetsugu ${ }^{\mathrm{a}}$, H. Shiobara $^{\mathrm{b}}$, H. Sugioka $^{\mathrm{a}}$, \\ J. Yoshimitsu ${ }^{\mathrm{a}}$, T. Kanazawa ${ }^{\mathrm{b}}$, Y. Fukao ${ }^{\mathrm{a}}$, G. Barruol ${ }^{\mathrm{c}}$ \\ a Institute for Research on Earth Evolution (IFREE), Japan Agency for Marine-Earth Science and Technology (JAMSTEC), 2-15 Natsushima-cho, Yokosuka 237-0061, Japan \\ ${ }^{\mathrm{b}}$ Earthquake Research Institute, University of Tokyo, 1-1 Yayoi, Bunkyo-ku, Tokyo 113-0032, Japan \\ ${ }^{\mathrm{c}}$ CNRS, University of Montpellier II, Eugène Bataillon, 34095 Montpellier Cedex 5, France
}

\begin{abstract}
A B S T R A C T
Three-dimensional P-wave velocity structure of the mantle beneath the South Pacific Superswell is determined through passive broadband seismic experiments on the ocean floor and islands between 2003 and 2005. We collected approximately 1500 relative times of long-period teleseismic P-waves by using a waveform cross-correlation. We analyzed this data set with relative time tomography to depths of $2000 \mathrm{~km}$. The resultant structure shows lateral heterogeneity of approximately $\pm 2 \%$, in which a distinct low velocity region is found beneath the center of the Superswell at a depth of $1600 \mathrm{~km}$. At $1200 \mathrm{~km}$ depth, an elongated low velocity region is found beneath the Society to Pitcairn hotspots. At $800 \mathrm{~km}$ depth, two linear low velocity regions are located beneath Tuamotu and Austral islands. Isolated low velocity regions are identified beneath the Society, Marquesas, and Macdonald hotspots at $400 \mathrm{~km}$ depth. Our new tomographic images reveal that the large low velocity region rooted in the deep lower mantle is split into two sheets at $1200 \mathrm{~km}$ depth and these terminate at approximately $800 \mathrm{~km}$ depth. This feature appears to be consistent with the characteristics of a thermo-chemical pile or dome.
\end{abstract}

\section{Introduction}

The South Pacific Superswell is characterized by a concentration of hotspots and their accompanying volcanic chains in French Polynesia and an anomalously shallow seafloor compared to the depth predicted by a seafloor subsidence model (Adam and Bonneville, 2005). However, the age progressions in the volcanic chains are of the order of 10 Myr or less in French Polynesia, which is much shorter than for the Hawaiian-Emperor seamounts (McNutt, 1998). In the Cook-Austral chains, three volcanic stages (58-40, 33-20, and 20-0 Ma) have been discovered through detailed dating of samples on the ocean floor and islands (Bonneville et al., 2006). So far six active hotspots (Society, Marquesas, Macdonald, Pitcairn, Rarotonga, Arago) are identified in the Superswell as shown in Fig. 1a (Bonneville et al., 2006; Courtillot et al., 2003). Furthermore, a negative geoid anomaly is predominant in the central part of French Polynesia (McNutt and Judge, 1990). These observations suggest the existence of diffuse upwellings distributed in the upper mantle beneath this region (McNutt, 1998). On the other hand, past superplume activity originating at the core-mantle bound-

\footnotetext{
* Corresponding author. Tel.: +81 46867 9340; fax: +81 468679315 E-mail address: stan@jamstec.go.jp (S. Tanaka).
}

ary in Cretaceous beneath the present location of the South Pacific Superswell has been hypothesized. This is discussed on the basis of geological evidence such as the coincidence of the high product rate of the oceanic crust and geomagnetic superchron (Larson, 1991a,b). However, the relationship between the present activity of upwelling in the lower mantle and the Superswell is still unclear.

In order to better constrain the dynamics and the present state of the deep mantle, seismic tomography is the most appropriate technique. Unfortunately, imaging of the seismic structure in the mantle beneath the South Pacific Superswell has been strongly limited by the little number of seismic stations available in this oceanic area, which could lead to a bleary and distorted picture in tomograms. This may explain large discordances among many tomographic models that have been published. For example, some have revealed a large-scale and vertically continuous low velocity anomaly throughout the mantle beneath hotspots in the South Pacific Ocean, and have discussed this in terms of the relationship between hotspots and a superplume or mantle plume as a simple and straightforward interpretation (Montelli et al., 2006; Zhao, 2004). On the other hand, some alternative models have shown that low velocity regions beneath the Pacific and Africa are confined to the lowermost mantle, up to approximately $1500 \mathrm{~km}$ depth, and that they do not continue throughout the whole mantle (Masters et al., 2000; Megnin and Romanowicz, 2000; Ritsema et 

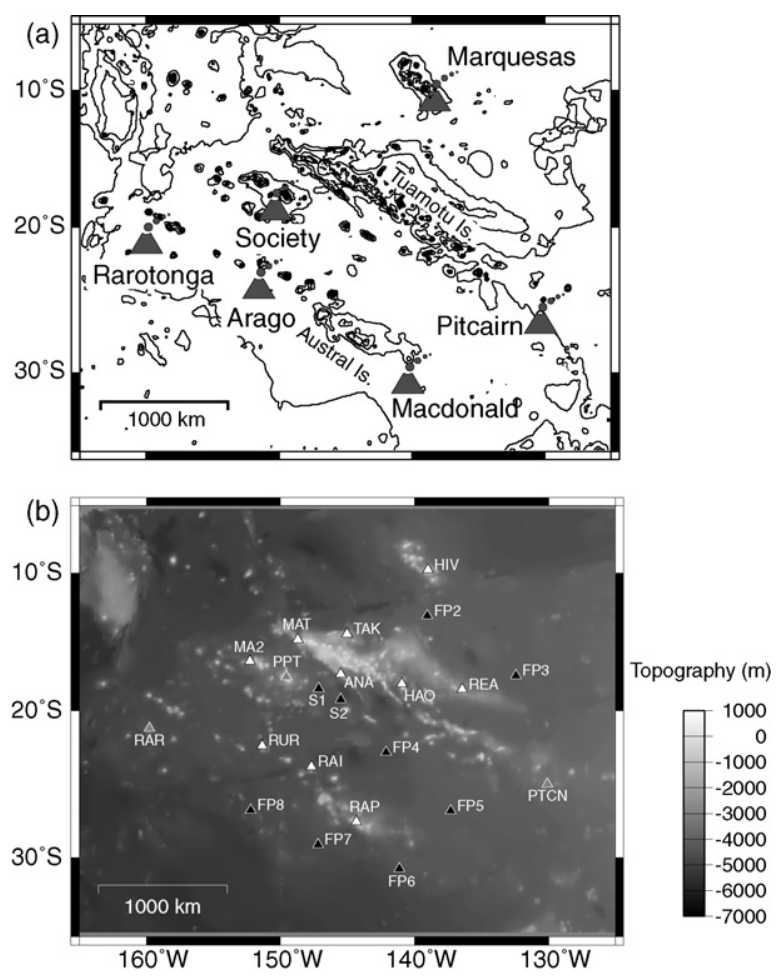

Fig. 1. (a) Bathymetry map of the South Pacific Superswell with the labels of the Tuamotu and Austral islands. The locations of major hotspots (Society, Marquesas, McDonald, Pitcairn, Rarotonga, and Arago) are marked by a volcano symbol. Contour interval for topography and bathymetry is $1000 \mathrm{~m}$. (b) Topography and bathymetry map of French Polynesia presenting the distribution of broadband seismic stations. Solid triangles surrounded with a white line are BBOBS, open triangles are PLUME, and gray triangles are IRIS and GEOSCOPE stations.

al., 1999). On the basis of these structures, thermo-chemical mantle convection resulting in a dome or pile is discussed in terms of numerical simulations and laboratory experiments (Davaille, 1999; McNamara and Zhong, 2004, 2005). Moreover, discussion on thermo-chemical mantle convection is also disputed. Thickness of the chemical boundary layer is proposed to be as thick as approximately $1000 \mathrm{~km}$ (Kellogg et al., 1999). Some numerical simulations of mantle convection assume a thin layer corresponding to the $\mathrm{D}^{\prime \prime}$ region (Tackley, 2002). Furthermore, the interpretation of a broad low velocity region is controversial. It can be the manifestation of an active upwelling or a passive pile that is swept by surrounding downwelling, which strongly depends on the nature of the mantle viscosity (Korenaga, 2005; McNamara and Zhong, 2004, 2005).

In order to provide arguments or answers to these questions and to better constrain the seismic structures in the upper and lower mantle beneath the South Pacific, a major effort was required to increase the seismic coverage in this remote part of the Pacific plate. Two passive and temporary seismic experiments have been conducted in the South Pacific Ocean; one consisted of deployment of broadband ocean bottom seismometers on the seafloor of French Polynesia between 2003 and 2005, referred as the FP-BBOBS project (Suetsugu et al., 2005). The other was the deployment of broadband seismographs on ocean islands, conducted between 2001 and 2005, and named the Polynesian Lithosphere and Upper Mantle Experiment (PLUME) (Barruol et al., 2002; Barruol et al., 2006). Data recorded by these experiments already provide important constraints on the possible plume signatures by imaging upper mantle structure and anisotropy from Rayleigh wave tomography (Isse et al., 2006; Maggi et al., 2006a,b), by mapping upper mantle flow from teleseismic shear wave splitting (Fontaine et al., 2007), or by characterizing the thickness of the transition zone from receiver function techniques (Suetsugu et al., 2007).

In the present study, we jointly analyze teleseismic P-wave travel times obtained from these two temporary experiments to explore the lower mantle seismic velocity structure. This paper mainly describes the procedure and results of a regional tomographic analysis in which only the data newly obtained by the experiments are used. Furthermore, we briefly examine the influence of the injection of the newly obtained data into the global whole-mantle tomography that uses preexisting data from the Bulletin of the International Seismological Center (ISC). Finally, we discuss the implications of our tomographic images for the dynamics in the mantle beneath the South Pacific Superswell.

\section{Data and methods}

We used seismograms recorded with the broadband ocean bottom seismographs (BBOBS) deployed during two independent periods; FP2-FP8 in the period from January 2003 to January 2004 (period 1), S1 and S2 in the period from August 2004 to June 2005 (period 2). We also included the data from the 10 broadband seismic stations of the PLUME temporary network deployed from November 2001 to August 2005, the permanent GEOSCOPE station PPT (Tahiti Island, French Polynesia), and the IRIS stations PTCN (Pitcairn Island, the United Kingdom) and RAR (Rarotonga, Cook Islands) for the two periods when the BBOBS were in operation. The locations of all the stations are presented in Fig. 1, together with the topography and the seafloor bathymetry and the hotspot locations. The BBOBS network was designed to fill the gaps between the island stations and the PLUME network. We selected earthquakes of magnitudes larger than 5.5, occurring at epicentral distances from the center of the network from $30^{\circ}$ to $100^{\circ}$. We picked up P-waveforms of 70 and 51 earthquakes in the periods 1 and 2, respectively. The geographic distribution of the epicenters used in the study is shown in Fig. 2. Hypocenter information was taken from the Earthquake Data Reports by the United States Geological Survey. In these two periods, earthquakes occurring in the southwestern Pacific were dominant in our data set. Therefore, we decided to weight the data corresponding to events arriving at FP4 (the central part of the network) with backazimuths of $260-280^{\circ}$ by $1 / 10$ throughout the regional tomography. A two-pole Butterworth filter with cutoff frequencies of 0.03 and $0.08 \mathrm{~Hz}$ (equivalent to the periods from 13 to $33 \mathrm{~s}$ ) was applied to the observed broadband seismographs because a low-noise level was observed in this frequency range (Barruol et al., 2006).

Relative travel times were measured by cross-correlation. Prior to the measurement, a record section for each event was prepared, in which the reference times of seismograms were aligned on the P-wave arrival times calculated from PREM (Dziewonski and Anderson, 1981) with correction of physical dispersion for the period of $13 \mathrm{~s}$ as shown in Fig. 3. In order to adjust different sampling

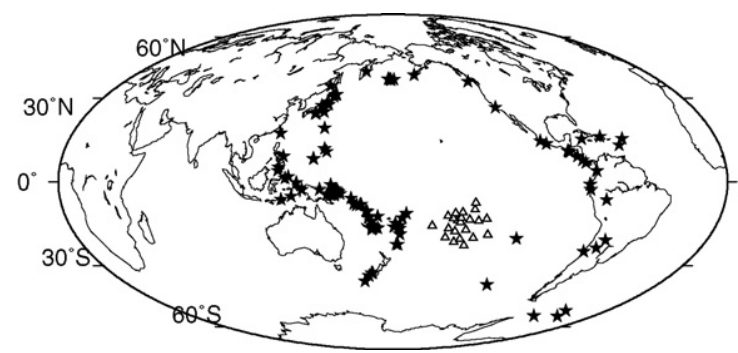

Fig. 2. Geographical distribution of the 121 epicenters (solid stars) and of the 22 seismic stations (open triangles) that are used in this study. 


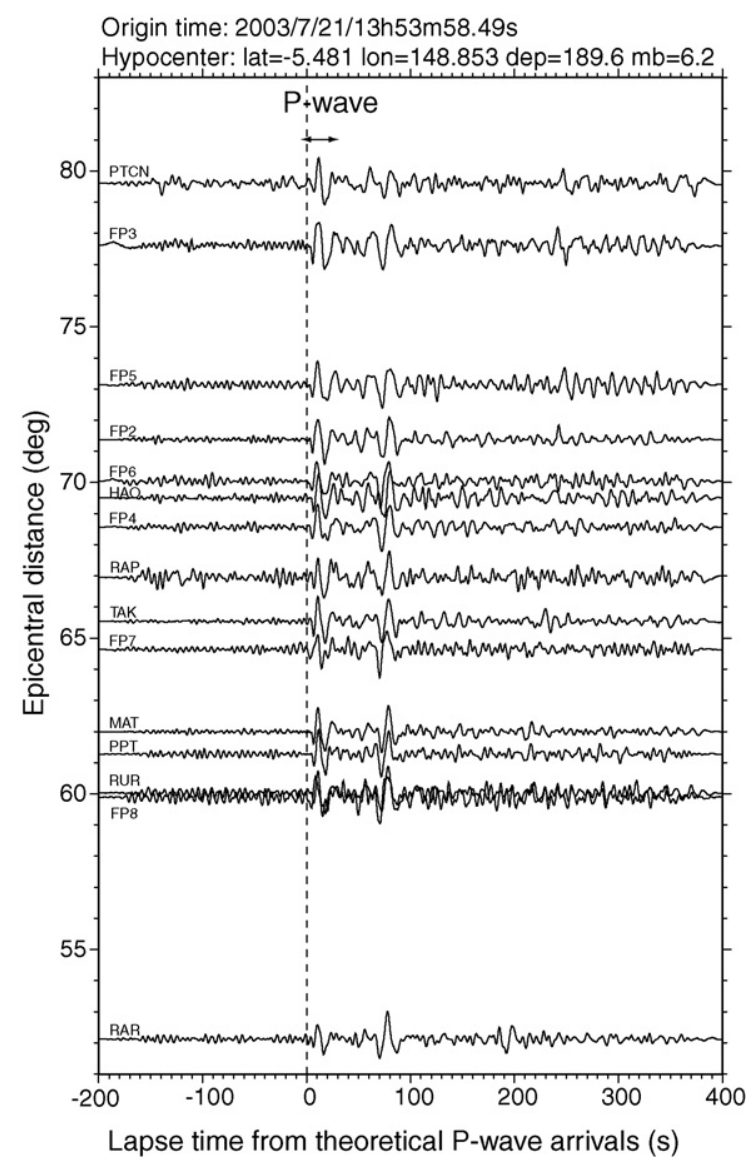

Fig. 3. Example of record section for an earthquake occurring in New Britain. Travel times are aligned on PREM theoretical P-wave arrival time. A two-pole Butterworth filter (13-33 s) was applied. The arrow at the top trace indicates the time window used for the cross-correlation measurement. frequencies among the observation systems $(128 \mathrm{~Hz}$ for BBOBS, $40 \mathrm{~Hz}$ for PLUME, and 20 or $40 \mathrm{~Hz}$ for IRIS and GEOSCOPE), the sampling interval of the digital seismogram was decimated to be $0.25 \mathrm{~s}$ $(=4 \mathrm{~Hz})$ after the relevant time shift. We did not adopt interpolation to adjust the sampling rate at higher values because we wanted to avoid the creation of unexpected artifacts and the $4 \mathrm{~Hz}$ sampling would be high enough for seismograms with a predominant period as long as the order of $10 \mathrm{~s}$. The reference pulse consists of a whole P-wave packet with a window length of $10-30$ s, which is taken from seismograms recorded at the station PPT, or at a BBOBS station with the best signal-to-noise ratio if PPT data were not available. Here, we adopt a single reference for simplicity, whereas similar studies have used the multi-reference cross-correlation method (VanDecar and Crosson, 1990). The reason is that the waveform similarity in the long-period components is very good. We finally obtained 1356 independent measurements that have correlation coefficients larger than 0.7 . We use them, together with the 121 reference times for further analyses. After applying the corrections of ellipticity (Kennett and Gudmundsson, 1996), the median values are finally subtracted from the relative times and the reference time for each event to provide 1477 residuals. This procedure aims at minimizing the influence of the hypocentral mislocation, source finiteness, and lateral heterogeneity outside the target region. The median value is adopted instead of the simple average because of its robustness. The ray distribution is presented in Fig. 4 and clearly features better coverage in the NW and NE quadrants.

We used the tomography code TOMOG3D2 (Zhao et al., 1992) which determines the velocity perturbations at grid points. The velocity perturbations at arbitrary locations are represented by linear interpolation of those at surrounding eight grid nodes. Horizontal grid nodes are put at $5^{\circ}$ and $6^{\circ}$ intervals for latitudes and longitudes (approximately $500 \mathrm{~km}$ ), respectively. The vertical grid interval is $400 \mathrm{~km}$. The grid configuration resulted in 269 unknowns for the velocity perturbation at grid points. The seismic ray locations are calculated using one-dimensional velocity model PREM with $10 \mathrm{~km}$ radial interval except in the neighborhood of the seismic discontinuities implemented in PREM. The seismic velocities are corrected for the period of $13 \mathrm{~s}$ according to a physical dispersion relation. However, precise ray perturbations with
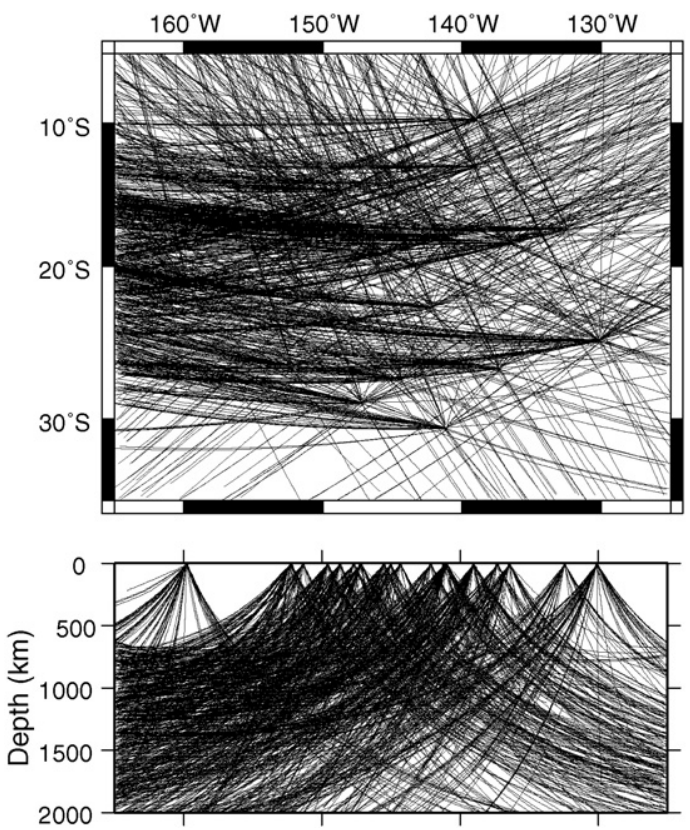

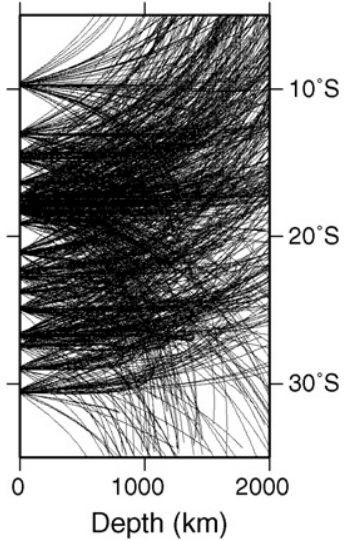

Depth $(\mathrm{km})$

Fig. 4. Geometry of the seismic rays used in this study, projected on the horizontal map, and along north-south and east-west cross-sections. 
three-dimensional heterogeneity are not considered since the grid interval is much wider than the ray fluctuation that is of the order of several tens kilometers (Zhao and Lei, 2004). The topography of the mantle discontinuities is not considered. Moreover, the diameter of Fresnel's zone $(\lambda L)^{1 / 2}$ ( $\lambda$ is wave length and $L$ is a ray length) for the long-period P-wave considering in this study is of the order of several hundred kilometers, which is a similar scale to the grid interval adopted here. Thus, we do not think that finite frequency effect is significant. Travel time data with absolute residuals $<2.0 \mathrm{~s}$ are retained and iteratively inverted to obtain the velocity perturbations and station terms by the LSQR (Paige and Saunders, 1982). The station terms would mainly represent the uppermost $200 \mathrm{~km}$ of the Earth just beneath the stations, and include the effects of topography and crustal heterogeneity, which are simultaneously estimated through the inversion (Benoit et al., 2003; Wolfe et al., 2002).

\section{Results}

Before inverting the observations, a checkerboard resolution test was conducted, in which $\pm 5 \%$ perturbations are alternately prescribed at the grid points. The travel time perturbations were calculated for the same combinations of events and stations as the observation. No additional noise was added to the calculated travel time data. The result of the inversion is shown in Fig. 5. Except for the solution at $2000 \mathrm{~km}$ depth where only the northern half area is well recovered, the solutions at the depths of $400,800,1200$, and $1600 \mathrm{~km}$ are well resolved for a wide area. Looking closely we can find that the well-solved regions at each depth are different from each other. At $400 \mathrm{~km}$ depth, only the central part surrounded by hotspots is well recovered. At $800 \mathrm{~km}$ depth, the recovered area becomes wider than that at $400 \mathrm{~km}$ depth. At 1200 and $1600 \mathrm{~km}$ depths, the recovered area shifts northward with increasing depth. The recovery rate is used for the presentation of the reliability in the tomographic images.

The final solutions for the observations are illustrated in Figs. 6-8. The weighted RMS residual is reduced from 0.48 to $0.27 \mathrm{~s}$ after three iterations. We confirm no significant improvement in the residuals with further increasing the number of iterations. Heterogeneity in the uppermost $200 \mathrm{~km}$ in the mantle is absorbed in the station terms as shown in Fig. 6. The station term of the station RAP is exceptionally large $(\sim 1.0 \mathrm{~s})$; the Macdonald hotspot is located nearby. On the other hand, that of the station FP8 exceeds $-0.5 \mathrm{~s}$. Moderate positive anomalies are found at PPT, FP4, and FP3. The geographical distribution of the station terms obtained by using the long-period seismograms is qualitatively consistent with the upper
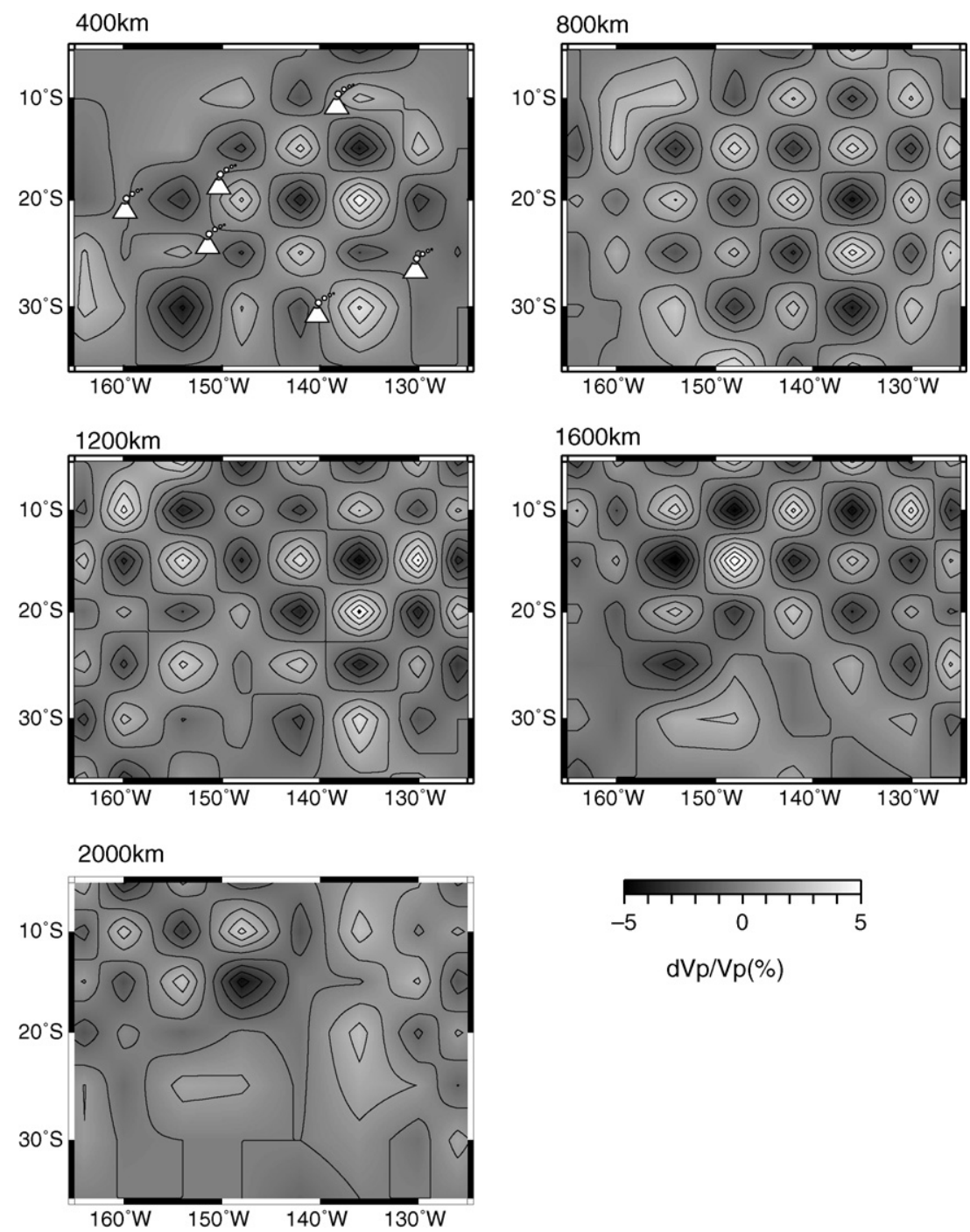

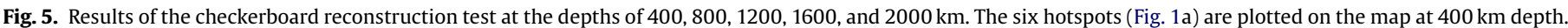
Contour intervals correspond to velocity perturbations of $1 \%$. The gray scale of the velocity perturbation is presented below. 


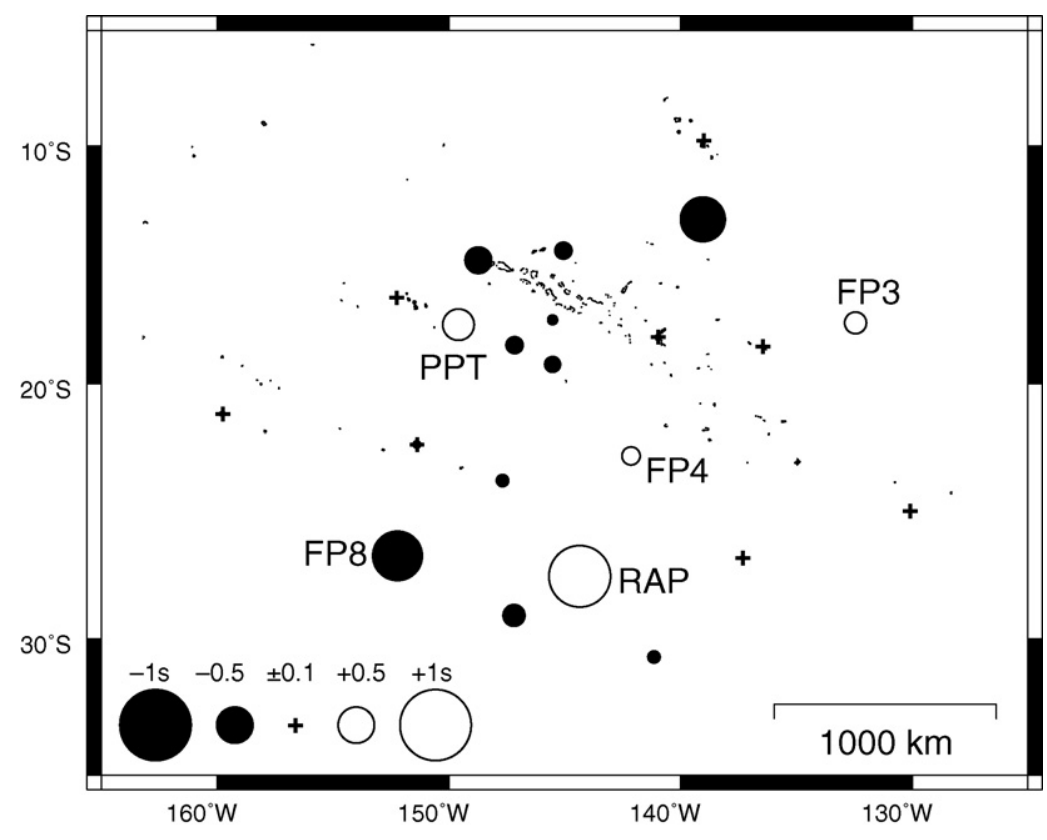

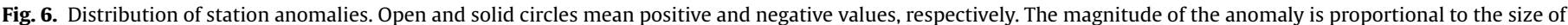
symbol as shown in the legend. Crosses indicate absolute values smaller than or equal to $0.1 \mathrm{~s}$.

mantle heterogeneity (Isse et al., 2006). On the other hand, when we pick the arrival times on the short period seismograms that are outputs of the band-pass filter with the period around $1 \mathrm{~s}$, the arrival times at the BBOBS stations are earlier by approximately $1 \mathrm{~s}$ than those at island stations. This suggests that the topography and crustal structure effects are strong at short periods. However, the geographical pattern of the station terms obtained above does not reflect the topography and crust structure, which would be healed in the long-period waveforms.

Fig. 7 illustrates the velocity perturbations at various horizontal depth slices, in which the perturbations are saturated at $\pm 2 \%$. Gray areas correspond to unconstrained regions with recovery rates smaller than 0.2. The most interesting feature is the distribution of the low velocity anomalies at each depth. In general, the size of the low velocity anomalies tends to be smaller toward the surface. At $1600 \mathrm{~km}$ depth, the northern area which represents $2 / 3$ of the target is well resolved and reveales low velocity anomalies located beneath the central part of the Superswell. At $1200 \mathrm{~km}$ depth, a linear trend of low velocity anomaly in the direction west-northwest to east-southeast is predominant beneath the Society to Pitcairn hotspots. At $800 \mathrm{~km}$ depth, two distinct low velocity anomalies can be found, which extend in the east-west direction. One runs alongside the north of the Tuamotu islands. Another one occupies the region from the west of the Pitcairn hotspot through the Austral islands. At $400 \mathrm{~km}$ depth, two low velocity anomalies are located just beneath the Society to Arago and Marquesas hotspots. Although reliability is low just beneath the Pitcairn hotspot, the northern and southern areas of Pitcairn are occupied by low velocity anomalies. The southern leg of the low velocity region reaches to the Macdonald hotspot.

Fig. 8 illustrates two vertical slices from the surface to $2000 \mathrm{~km}$ depth passing through two of the major hotspots. These crosssections running almost east-west (denoted as AB in Figs. 7 and 8) and north-south (denoted as CD in Figs. 7 and 8 ) have the same color scale as the horizontal slices. The less reliable area is masked. In the vertical EW cross-section through the Society and Pitcairn hotspots (the $A B$ cross-section), we observe that the low velocity region occupies a huge volume in the lower mantle. The low velocity appears to be initiated below $1600 \mathrm{~km}$ depth and elon- gates upward and spreads laterally at $1200 \mathrm{~km}$ depth. This large, low velocity region is approximately $3000 \mathrm{~km}$ long (corresponding to angular distance of about $30^{\circ}$ ) at this depth. This low velocity region reaches approximately $800 \mathrm{~km}$ depth beneath the Superswell. On the other hand, a low velocity region beneath the Society hotspot solitarily exists at $400 \mathrm{~km}$ depth, compatible with the lowvelocity body observed by Rayleigh wave tomography of this area (Maggi et al., 2006b). In the vertical NS cross-section through the Marquesas and Macdonald hotspots (the CD cross-section), a large low velocity region present below $1600 \mathrm{~km}$ depth appears to break up at $1200 \mathrm{~km}$ depth, and is completely separated into two branches at $800 \mathrm{~km}$ depth. As seen in Fig. 7, these two low velocity regions at $800 \mathrm{~km}$ depth are approximately $1000 \mathrm{~km}$ long in the direction perpendicular to this cross-section. The northern branch of the low velocity culminates at $400 \mathrm{~km}$ depth beneath the Marquesas hotspot (near the point $\mathrm{D}$ ). The overall feature of the low velocity region beneath the South Pacific Superswell suggests to us that a large low velocity body visible in the deeper part of the lower mantle spreads into two oblique sheets in the upper part (see Fig. 8b) rather than branching columns or narrow plumes.

\section{Verification}

Although the tomographic images are derived from only the highest quality and most reliable data, there are likely uncertainties attributed to the method of the regional tomography itself. In this section, we intend to verify the results derived in the previous section.

\subsection{Effects of a one-dimensional reference model}

We have implicitly assumed that the one-dimensional reference model is correct or does not significantly differ from a correct one. However, this assumption is not always guaranteed. Furthermore, the pattern of the velocity perturbation may provide a different impression if we use another models instead of PREM used in the previous section. Therefore, we exchange the 1D reference model by adopting a regional 1D structure that is derived from the whole mantle P-wave tomographic model WEPP2' (Fukao et al. 

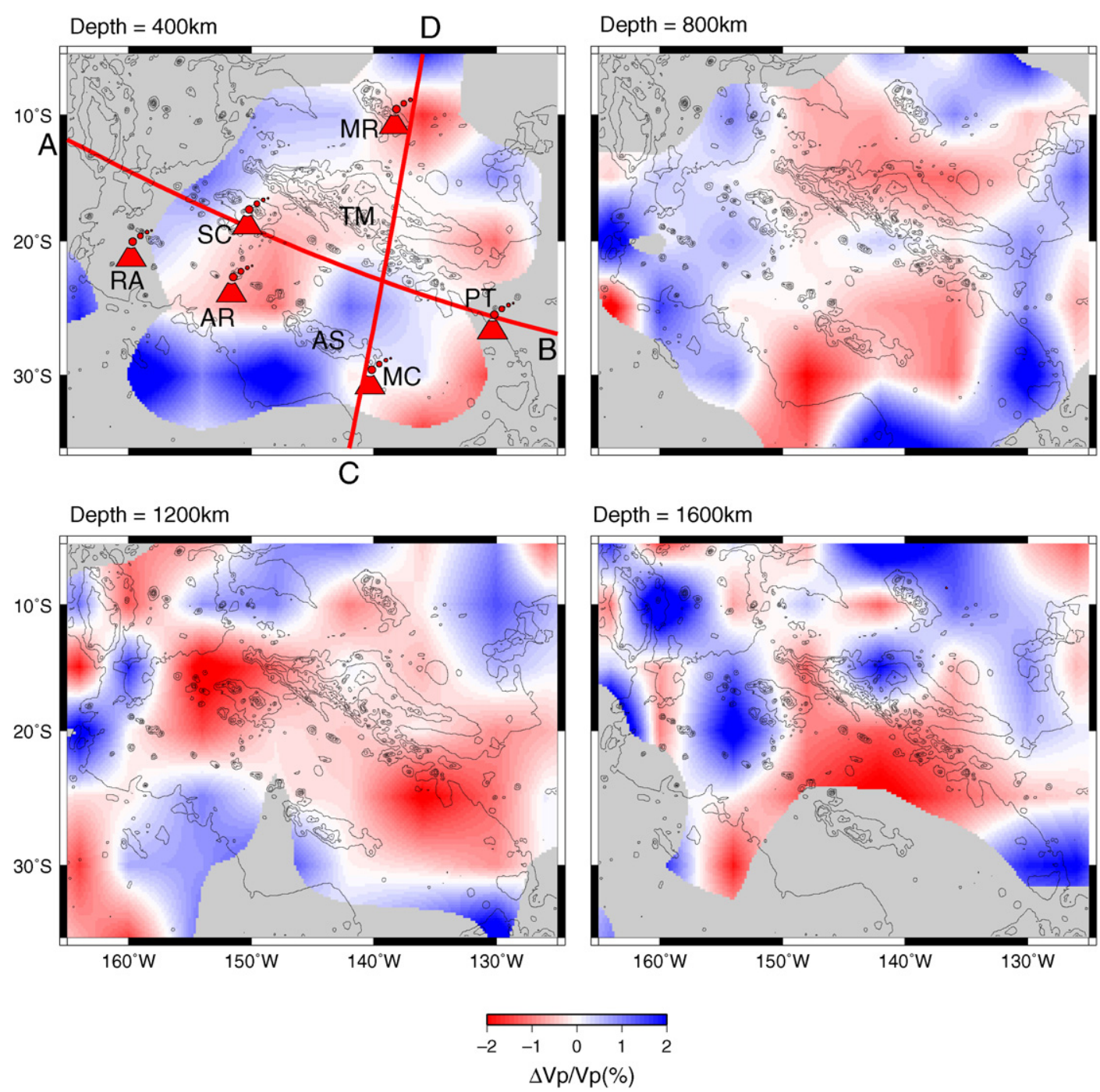

Depth $=1600 \mathrm{~km}$

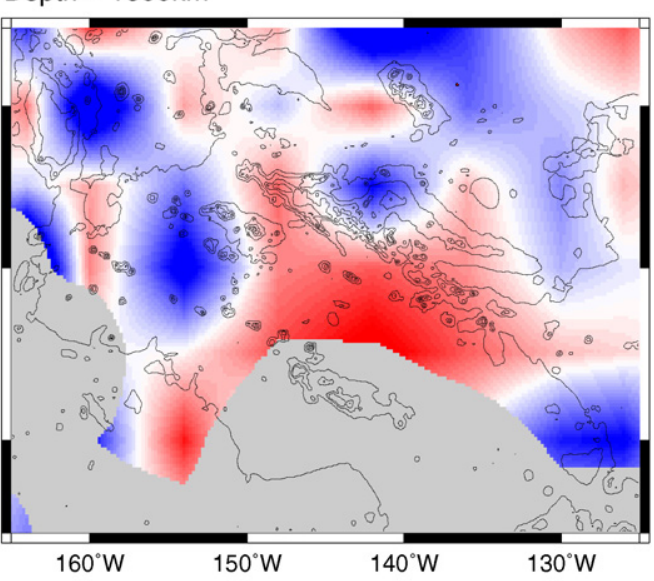

$\mathrm{Vp} / \mathrm{Vp}(\%)$

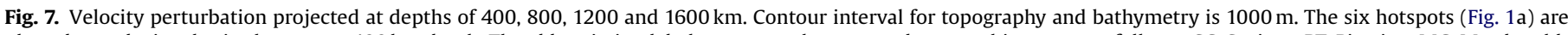

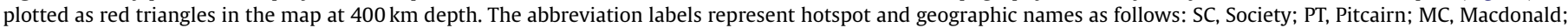
MR, Marquesas; RA, Rarotonga; AR, Arago; TM, Tuamotu Is.; AS, Austral Is.

2003). Considering the ray coverage, we take the average structure bounded at $50^{\circ} \mathrm{S}$ and $10^{\circ} \mathrm{N}$ for north-south direction and at $110^{\circ} \mathrm{W}$ and $180^{\circ}$ for east-west direction, hereafter we refer as WEPP2'_FP. Fig. 9a shows the P-wave velocity profiles of WEPP2'_FP and PREM incorporating the $Q$ correction for the period of $13 \mathrm{~s}$ that is used in the previous sections (referred as PREM@13s) as a function of radius. It is clearly found that the velocity profiles of WEPP2'_FP are smoothed around all the mantle discontinuities. Fig. 9b shows the difference of the P-wave velocities with respect to that of PREM@13 s. The velocity profiles of WEPP2'_FP and WEPP2' that is the global average are presented for comparison, which indicates that the differences between WEPP2'_FP and WEPP2' are very small, but the P-wave velocities of WEPP2'_FP are slightly slower than those of WEPP2 in the lower mantle. However, the WEPP2' models have large velocity differences in the upper mantle with respect to PREM. These differences would be originated from data set used in the model construction and from the setting of model parameterization. Except for the upper mantle and adjacent regions near the mantle discontinuities, the velocity differences of WEPP2' ${ }^{\prime} \mathrm{FP}$ for PREM@13 s in the lower mantle are less than 0.5\%, the lowest peak being approximately located at $2750 \mathrm{~km}$ depth, $150 \mathrm{~km}$ above the core-mantle boundary. The velocities are about $0.2 \%$ slower in the lower half of the lower mantle and are about $0.1 \%$ slower in the mid lower mantle.

The data of the travel time residuals used in the previous section were corrected for the new reference model of WEPP2'_FP instead of PREM@13 s. A new median value was determined for each event and we finally subtracted it to obtain a new data set. In a tomographic inversion, seismic rays were traced with WEPP2' ${ }^{\prime}$ FP. We show the resultant tomographic images projected on the vertical cross-sections (Fig. 10) in the same orientations and with the same masked area that in Fig. 8. Overall features in Figs. 8 and 10 are similar to each other even though the different 1D structures are used. We observed the large low velocity region in the depth range $1600-1200 \mathrm{~km}$ in the EW cross-section (Fig. 10a) and that splits around $1200 \mathrm{~km}$ depth into two branches at $800 \mathrm{~km}$ depth in the NS cross-section (Fig. 10b). Only some differences are visible in the upper mantle even though the large differences are found in the 1D structure. The low velocity region beneath the Society hotspot found in Fig. 10a is larger than that in Fig. 8a. The low velocity region beneath the Macdonald hotspot (near the point $\mathrm{C}$ ) is present at the depth of $400 \mathrm{~km}$ in Fig. 10b, whereas it is not so significant in Fig. 8b. The low velocity region beneath the Marquesas hotspot (near the point D) in Fig. 10b is smaller than that in Fig. 8b. In summary, 


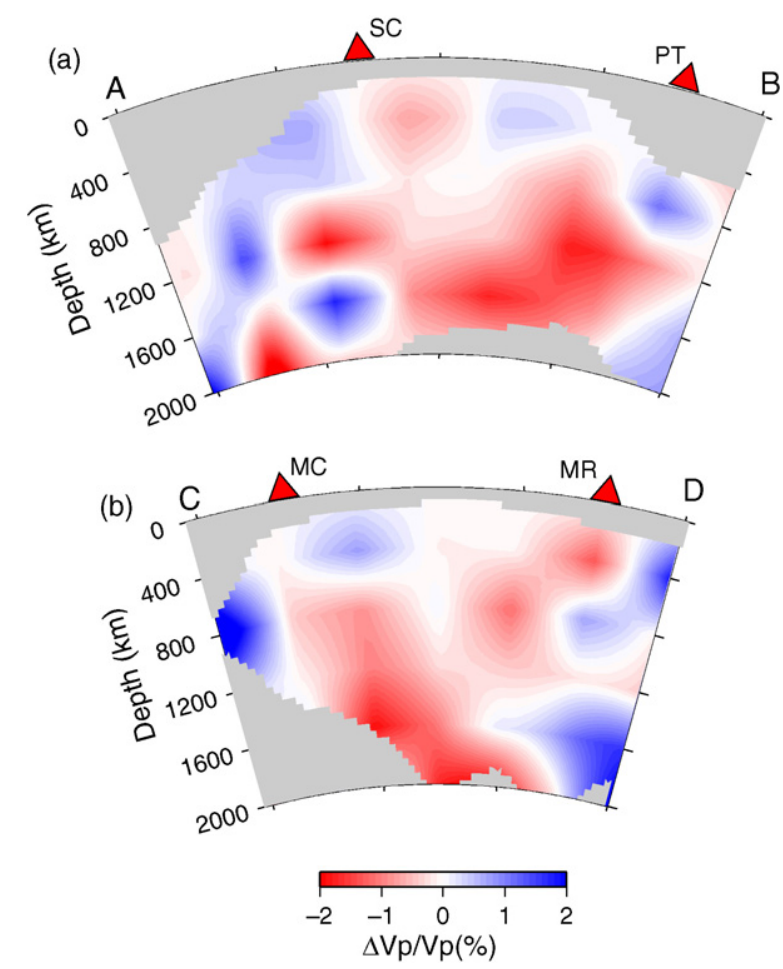

Fig. 8. Velocity perturbation projected along the vertical cross-sections through the Society and Pitcairn hotspots (the AB cross-section) (a), and through the Marquesas and Macdonald hotspots (the CD cross-section) (b). The color scale of the $\pm 2 \%$ velocity perturbation is presented below. Red triangles show hotspot locations. The abbreviation labels represent hotspot names as follows: SC, Society; PT, Pitcairn; MC, Macdonald; MR, Marquesas.

the tomographic images do not show significant differences in the lower mantle even if the 1D structure is replaced.

\subsection{Injection of the new temporary data into whole-mantle tomography}

In order to consider the effects of mantle heterogeneity outside the target region, a whole-mantle tomography using absolute travel times and differential travel times measured from that at a reference station is performed in this section. In the whole-mantle P-wave tomography, the ISC data is predominant in the construction of the tomographic image. Unfortunately, the ISC data may contain unreliable data and it would be difficult to control and homogenize the data quality. Furthermore, there is a difficulty to reconcile the new travel time measurements and the ISC data. We thus, tentatively assign two weights on the new data (10 and 1000) and analyze their effects on the results.

Introducing the French Polynesia newly acquired data described in the previous section should modify the whole mantle P-wave tomographic model, and should regionally increase its resolution. We used WEPP2' (Fukao et al., 2003) as an initial model. This model is derived from approximately 7 million P-wave arrival times reported in the ISC bulletin and about 7000 PP-P differential travel times measured on global broadband seismograms with a correction for time shifts due to the crustal reverberations (Obayashi et al., 2004). The relative times of the long-period P-waves obtained in the previous section were converted to differential travel times with a reference to P-wave arrival times, $T_{\text {P-Pref }}$, for each event. We adopted the travel time at the station of the shortest epicentral distance as the reference. Hence, $1356 T_{\text {P-Pref }}$ were used as independent data. Additionally, we included approximately 600 absolute
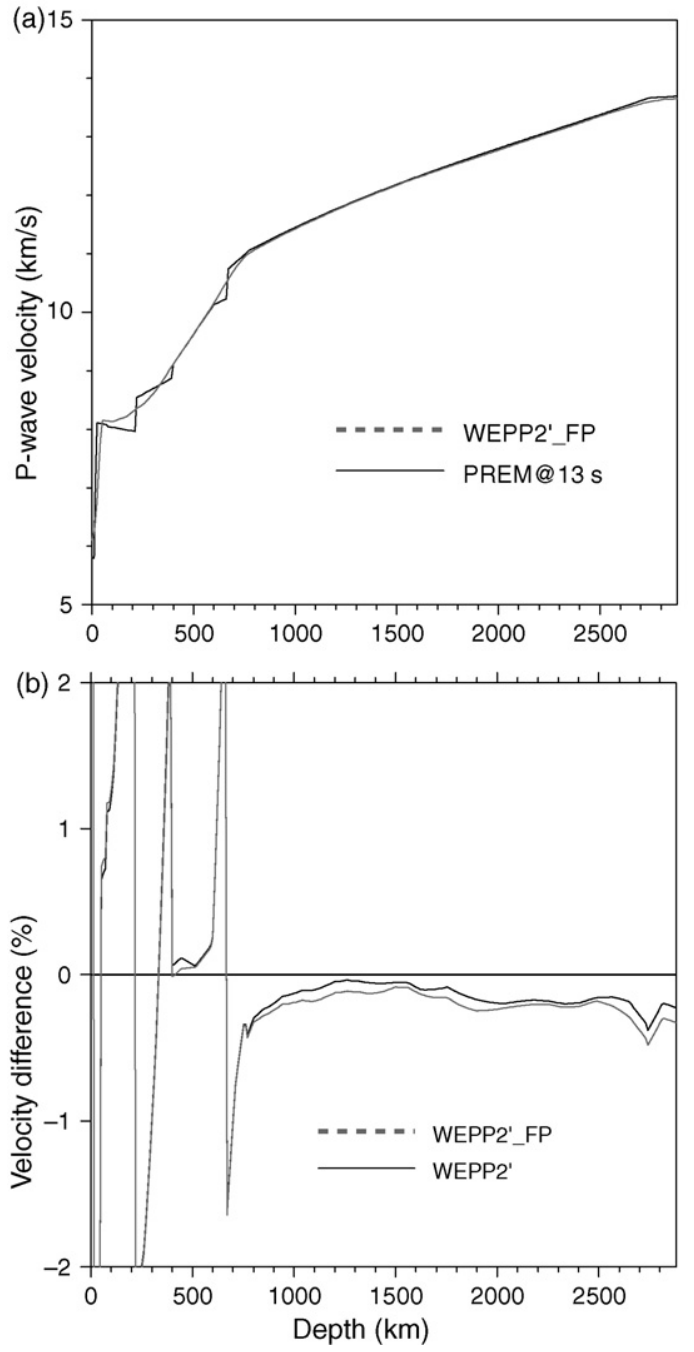

Fig. 9. (a) P-wave velocity in the mantle as a function of depth. Solid and dashed lines are PREM@13 s and WEPP2'_FP, respectively. (b) Depth variations of velocity differences with respect to PREM@13 s. Solid and dashed lines are WEPP2' and WEPP2'_FP, respectively.

P-wave arrival times that were manually picked on the seismograms through a band pass filter with the short period of $1 \mathrm{~s}$.

The basic inversion procedure and the model parameterization are the same as the pioneering study of Inoue et al. (1990). To compare a new whole mantle tomography image with the regional one obtained in the previous section, we adopted the regular block parameterization rather than the irregular one in which blocks become finer according to the ray density (Fukao et al., 2003). The mantle region was divided into blocks with the horizontal size of approximately $5^{\circ}$ for latitude and longitude, the thickness of a block increasing with depth. For example, it is $151 \mathrm{~km}$ thick for the block with its top located at $478 \mathrm{~km}$ depth and $232 \mathrm{~km}$ thick at $1203 \mathrm{~km}$ depth. In the inversion, we assigned the weight of factor 10 or 1000 to the new data, since a great number of the ISC data should overwhelm the contribution of the new data if we assign an equal weight to all the data.

Fig. 11 shows the velocity perturbations projected on the vertical cross-sections that are same as in Fig. 8. The images of the whole mantle tomography are obtained by linear interpolation of the velocity perturbations that is assumed to be located at the centers of the blocks. The magnitude of the velocity perturbations for the weight of 10 is smaller than that for the weight of 1000 . 


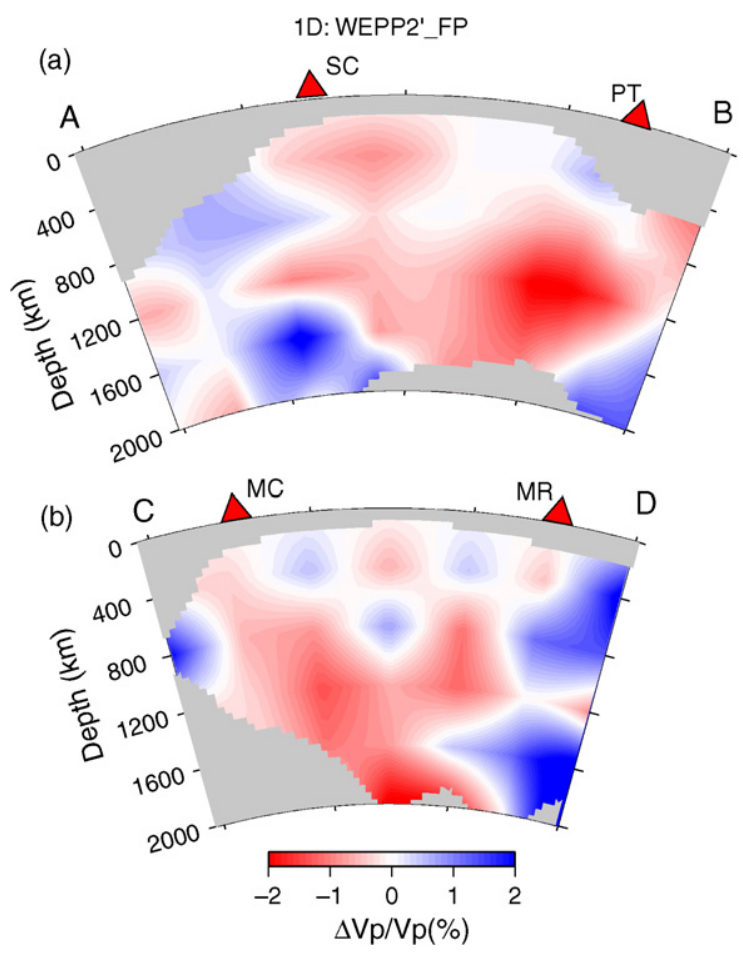

Fig. 10. Velocity perturbation obtained by using WEPP2' $2^{\prime}$ PP as the $1 \mathrm{D}$ reference structure, projected along the vertical cross-sections through the Society and Pitcairn hotspots (the AB cross-section) (a), and through the Marquesas and Macdonald hotspots (the CD cross-section). (b) The color scale of the $\pm 2 \%$ velocity perturbation is presented below. Red triangles show hotspot locations. The abbreviation labels represent hotspot names as follows: SC, Society; PT, Pitcairn; MC, Macdonald; MR, Marquesas.

The low velocity region in the whole upper mantle is predominant especially in the image for the weight of 1000 (Fig. 11b). This feature is apparently different from those in the regional tomography. However, the regional tomography basically solves only the lateral variations from an arbitrary average at each depth, whereas the average velocity remains unknown. On the other hand, the image from the whole-mantle tomography shows velocity perturbation strictly from the global average. The present result indicates the mean velocity in the upper mantle is much slower than that of the global average. Such a result was also observed in the $S$-wave velocity structure deduced from the surface wave analysis (Isse et al., 2006). Considering that the characteristic pattern of the lower mantle structure is insensitive to 1D structure as seen in the previous section, we prefer to focus the discussion on the heterogeneity pattern found in the lower mantle.

The most predominant feature in the east-west (AB) crosssection is a large low velocity zone at depths of about $1200 \mathrm{~km}$ that extends laterally. This feature is found in the tomographic images for the data weights of 10 and 1000 (Fig. 11a and b) and is quite similar to that obtained in the regional tomographic image (Fig. 8a). A gap of the low velocity zones is found in the uppermost lower mantle in both images for the different data weights. On the other hand, the images of the north-south (CD) cross-section do not resemble each other (Fig. 11a and b). In the image for weight of 10, a low velocity zone exists beneath the Marquesas hotspot (near the point $\mathrm{D}$ ) at about $1000 \mathrm{~km}$ depth, and the low velocity zone is continuous down to about $1500 \mathrm{~km}$ depth beneath the central part of the Superswell (Fig. 11a). However, the image for the weight of 1000 shows that a low velocity located in the deep lower mantle beneath the central part of the Superswell splits at $1200 \mathrm{~km}$ depth into two branches at depth about $1000 \mathrm{~km}$ (Fig. 11b). The later image is similar to that in the $\mathrm{CD}$ cross-section by the regional tomography (Fig. 8b). Since the large weight data set leads to such a branched low velocity region, a blurry low velocity body in the mid-mantle (the CD cross-section in Fig. 11a) may be attributed to poor coverage of the ISC data.

In summary, all the images along the east-west cross-sections obtained by the regional and whole-mantle tomographies show similar features. Furthermore we find that the whole-mantle tomography calculated with a large weight for the new French Polynesia data reveals a similar image to that obtained by the regional tomography even in the north-south cross-section. One may thus, consider that the regional tomographic images presented in Figs. 7 and 8 are reliable features.

\section{Discussion}

Since the concept of the South Pacific Superswell was first proposed by McNutt and Fischer (1987), the process of its origin has been widely discussed. Originally, the thinning of the plate was considered as a dominant cause to explain the anomalous seafloor depths (McNutt and Fischer, 1987). An alternative hypothesis implying an upwelling in the upper mantle was proposed to explain the satellite altimetry data and the negative geoid anomaly (McNutt and Judge, 1990). On the basis of tomographic models available at that time, McNutt (1998) tentatively proposed that the hot material under the South Pacific Superswell is not fed by upwelling from the lower mantle and is distinct from plumetype activities because of the apparent absence of the continuous low velocity anomaly in the lower mantle beneath the region. The recent progress in seismic tomography has strongly increased the resolution of the deep mantle imaging and argued for a deep source of this Superswell anomaly. Although, this discussion is still opened, a recent study (Adam and Bonneville, 2005) proposes a lower mantle source of the dynamic support of the South Pacific Superswell compatible with the large, low velocity region at lower mantle depths beneath this area. Geodynamical discussions are, however, rather conflicting, since they strongly depend on the interpretation of the large seismic low velocity region in the lower mantle. If the broad low velocity province is not an assembly of narrow low velocity columns, this large size can be explained by a thermo-chemical plume that forms a dome structure (Davaille, 1999; Farnetani and Samuel, 2005) or a pile that is passively constructed by neighboring downwellings (McNamara and Zhong, 2004).

The origin of the individual hotspots above the South Pacific Superswell is also controversial. Except for the Marquesas, Courtillot et al. (2003) classified the hotspots in French Polynesia as secondary hotspots that could be generated beneath the transition zone, at the head of a superplume. Hotspot tracks, flood basalts, buoyancy fluxes, helium isotope ratio and shear-wave velocity anomalies are considered by theses authors to discriminate whether hotspots originate from deep mantle or have shallower origin. Recent tomographic studies show a large-scale low velocity region in the lower mantle beneath the South Pacific Ocean that may support the existence of such a superplume (Zhao, 2001, 2004). On the other hand, P-wave tomographic image using finitefrequency kernels evidences a pillar-like low velocity structure extending throughout the mantle beneath the Society hotspot, with a poor resolution in the mid-mantle between 1000 and $1450 \mathrm{~km}$ depths (Montelli et al., 2004, 2006). However, even in the most recent global tomographic study, the spatial resolution is not improved in this area (Li et al., 2008). Although the original definition of a pure thermal plume describes it as a narrow conduit with a spherical head (Morgan, 1971; Olson and Nam, 1986), the seismological images clearly depart from this description (Nataf, 2000) providing argument to criticize a hotspot-mantle plume hypothesis itself (Foulger and Natland, 2003). 
(a) Weight: $\times 10$
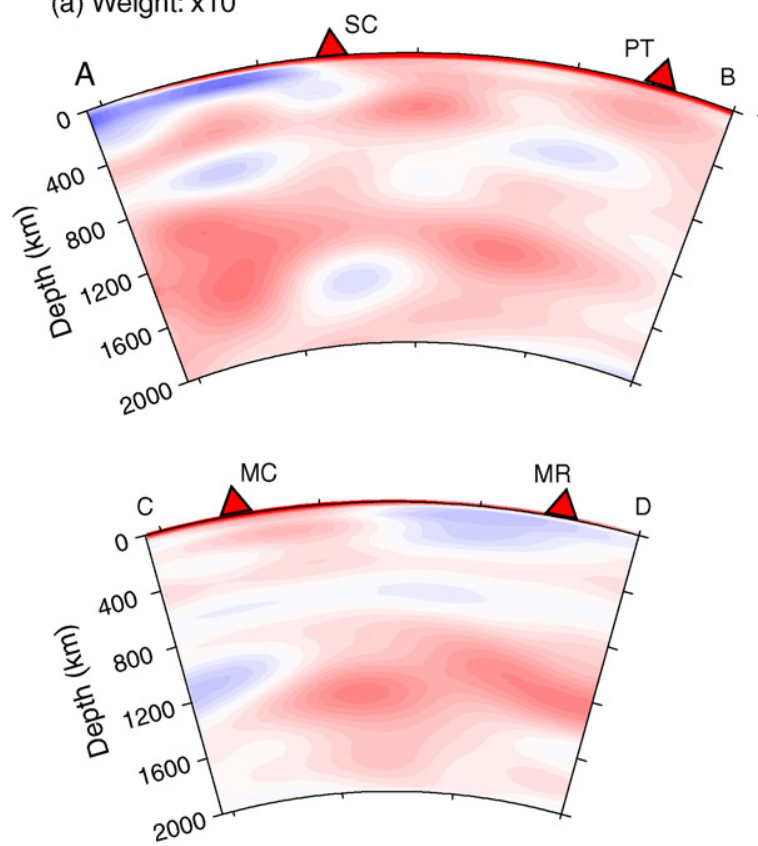

(b) Weight: $x 1000$
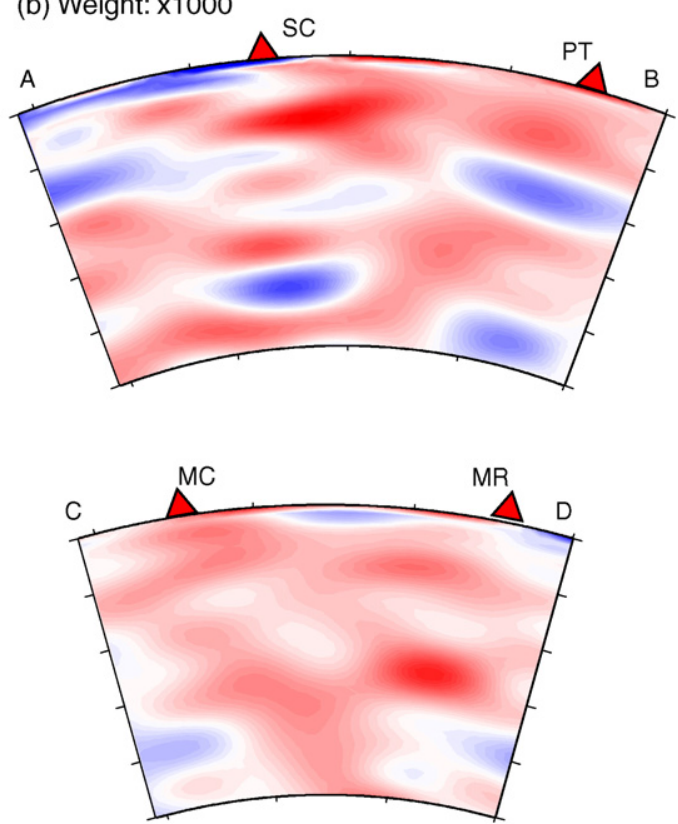

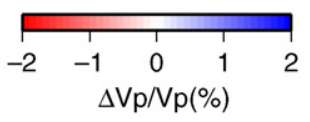

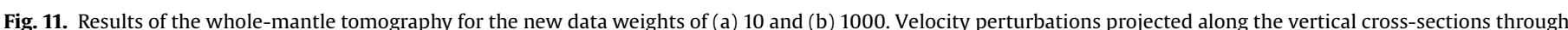

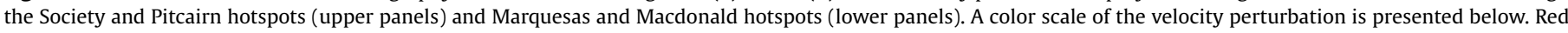
triangles show hotspot locations. The abbreviation labels represent hotspot names as follows: SC, Society; PT, Pitcairn; MC, Macdonald; MR, Marquesas.

The seismic images shown in the present study by using the regional tomography revealed large-scale robust features. However, we must keep in mind that the tomographic images in this study have to be improved by future observations. Moreover, the shape of the P-wave low velocity region alone is not enough to distinguish between a thermal plume and chemical pile. Even though we have such strong limitation in interpreting our tomographic images, they clearly do not support a classical image of a mantle plume described as a large spherical head over a narrow stem. The tomographic images primarily show a large-scale low velocity region in the lower mantle beneath the center of the South Pacific Superswell culminating at approximately $800 \mathrm{~km}$ depth, and some individual low velocity regions in the upper mantle beneath some of the hotspots such as the Society and Marquesas. Second, the large low velocity region in the deeper part of the lower mantle splits into two sheets at $1200 \mathrm{~km}$ depth (see Fig. $8 \mathrm{~b}$ ). As suggested by the tomographic image, it is likely the two sheets in the upper part of the lower mantle could correspond to the deep roots of the Marquesas and Macdonald hotspots.

One possible interpretation of the large-scale P-wave low velocity regions is the manifestation of a hot upwelling activity with chemical anomaly in the lower mantle. This supports the proposition of Davaille (1999) and Courtillot et al. (2003) who suggested that the Superswell is formed by a superplume or a dome associated with secondary plumes at the origin of the individual hotspots. Another important observation is that the low velocity region in the lower mantle extends in the east-west direction and is narrower along the north-south direction (see Fig. 7 for the image at $1200 \mathrm{~km}$ depth). This feature might be affected by mantle convection as discussed by McNamara and Zhong (2005) who reproduce a ridgelike and dense anomaly near the base of the mantle beneath the Africa in their simulation, whereas the shape of the dense anomaly beneath the Pacific Ocean is rather rounded. Therefore, the relationship between the shape of the low-velocity region in the lower mantle and downwelling flows around the Pacific Ocean should be further examined.

\section{Conclusions}

Teleseismic tomography using relative time residuals has revealed a large-scale P-wave low velocity region in the lower mantle beneath the center of the South Pacific Superswell by using broadband seismographs that were temporally deployed at the seafloor and islands in French Polynesia. Long-period Pwaves have been collected and yield approximately 1500 relative times. The regional tomography reveals a large, low velocity region located at depths from below 1600 to $800 \mathrm{~km}$ that splits into two sheets around $1200 \mathrm{~km}$. The tomography shows that the aspect of the large low velocity region in the lower mantle is characterized by an east-west extension. Low velocity regions in the upper mantle beneath the individual hotspots are mapped and some could be associated with low velocity branches toward the head of the large-scale low velocity region in the lower mantle. These features are consistent with some characteristics of upwelling flows predicted by thermo-chemical mantle convection. 


\section{Acknowledgements}

The French Polynesia BBOBS array was deployed by a collaborative project of Japan and France. We thank Captains Sadao Ishida and Fusao Saito, the crew of R/V YOKOSUKA, the Shinkai6500 operation team, the JAMSTEC administration for enabling the deployment and recovery of the FP-BBOBS. PLUME was funded by the French Ministère de la Recherche, Action Concertée Incitative (ACI) jeunes chercheurs. Many thanks to the Center National de la Recherche Scientifique (CNRS), to the Government of French Polynesia, to the Université de Polynésie Française (UPF), to the Haut-Commissariat de la Polynésie française, to the Commissariat à l'Energie Atomique (CEA) to Météo France and to the Aviation Civile for having made this experiment possible. We thank Dominique Reymond, Alain Bonneville, François Schindelé, and Eric Debayle for the cooperation. Local support by Dominique Reymond was particularly important. Thanks to IRIS and GESCOPE networks that provide high quality broadband seismograms and to USGS that provides hypocenter information. D. Zhao kindly provides us with his tomography code. Comments by C. Adam were helpful to improve the manuscript. We are grateful to T. Lay for his encouragement and kind help to refine our English expression. We also thank an anonymous reviewer for valuable comments, G. Helffrich for his editorial efforts. The GMT system (Wessel and Smith, 1998) was used for the preparation of the figures. The present study is supported by a Grant-in-Aid for Scientific Research (A) No. 16253002 and No. 19253004 from the Japan Society for the Promotion of Science.

\section{References}

Adam, C., Bonneville, A., 2005. Extent of the South Pacific Superswell. J. Geophys. Res. 110 (B9), doi:10.1029/2004JB003465

Barruol, G., Bosch, D., Clouard, V., Debayle, E., Doin, P., Fontaine, F.R., Godard, M. Masson, F., Reymond, D., Tommasi, A., Thoraval, C., 2002. PLUME investigates South Pacific Superswell. EOS Trans. Am. Geophys. Union 83, 511-514.

Barruol, G., Reymond, D., Fontaine, F.R., Hyvernaud, O., Maurer, V., Maamaatuaiahutapu, K., 2006. Characterizing sells in the southern Pacific from seismic infrasonic noise analysis. Geophys. J. Int. 164, 516-542, doi:10.1111/J.1365 246X.2006.02871.X

Benoit, M.H., Nyblade, A.A., VanDecar, J.C., Gurrola, H., 2003. Upper mantle P-wave velocity structure and transition zone thickness beneath the Arabian Shield. Geophys. Res. Lett. 30, doi:10.1029/2002GL016436.

Bonneville, A., Dosso, L., Hildenbrand, A., 2006. Temporal evolution and geochemical variability of the South Pacific superplume activity. Earth Planet. Sci. Lett. 244 (1-2), 251-269.

Courtillot, V., Davaille, A., Besse, J., Stock, J., 2003. Three distinct types of hotspots in the Earth's mantle. Earth Planet. Sci. Lett. 205, 295-308.

Davaille, A., 1999. Simultaneous generation of hotspots and superswells by convec tion in a heterogeneous planetary mantle. Nature 402, 756-760.

Dziewonski, A.M., Anderson, D.L., 1981. Preliminary reference Earth model. Phys Earth Planet. Int. 25 (4), 297-356.

Farnetani, C.G., Samuel, H., 2005. Beyond the thermal plume paradigm. Geophys. Res. Lett. 32, doi:10.1029/2005GL022360.

Fontaine, F.R., Barruol, G., Tommasi, A., Bokelmann, G.H.R., 2007. Upper-mantle flow beneath French Polynesia from shear wave splitting. Geophys. J. Int. 170, 1262-1288, 1210.1111/j.1365-1246X.2007.03475.X.

Foulger, G.R., Natland, J.H., 2003. Is "Hotspot" volcanism a consequence of plate tectonics? Science 300, 921-922.

Fukao, Y., To, A., Obayashi, M., 2003. Whole mantle P-wave tomography using $P$ and PP-P data. J. Geophys. Res. 108 (B1), doi:10.1029/2001JB000989.

Inoue, H., Fukao, Y., Tanabe, K., Ogata, Y., 1990. Whole mantle P-wave travel time tomography. Phys. Earth Planet. Int. 59, 294-328.

Isse, T., Suetsugu, D., Shiobara, H., Sugioka, H., Yoshizawa, K., Kanazawa, T., Fukao, Y., 2006. Shear wave speed structure beneath the South Pacific superswell using broadband data from ocean floor and islands. Geophys. Res. Lett. 33, L16303, doi:10.1029/2006GL026872.

Kellogg, L.H., Hager, B.H., van der Hilst, R.D., 1999. Compositional stratification in the deep mantle. Science 283, 1881-1884.
Kennett, B.L.N., Gudmundsson, O., 1996. Ellipticity corrections for seismic phases. Geophys. J. Int. 127, 40-48.

Korenaga, J., 2005. Firm mantle plumes and the nature of the core-mantle boundary region. Earth Planet. Sci. Lett. 232 (1-2), 29-37.

Larson, R.L., 1991a. Latest pulse of Earth: evidence for a mid-cretaceous superplume. Geology 19, 547-550.

Larson, R.L., 1991b. Geological consequences of superplumes. Geology 19, 963-966.

Li, C., van der Hilst, R.D., Engdahl, E.R., Burdick, S., 2008. A new global model for Pwave speed variations in Earth's mantle. Geochem. Geophys. Geosys. 9, Q05018, doi:10.1029/2007GC001806.

Maggi, A., Debayle, E., Priestley, K., Barruol, G., 2006a. Azimuthal anisotropy of the Pacific region. Earth Planet. Sci. Lett. 250 (1-2), 53-71, doi:10.1016/j.epsl.2006.07.010.

Maggi, A., Debayle, E., Priestley, K., Barruol, G., 2006b. Multimode surface waveform tomography of the Pacific Ocean: a closer look at the lithospheric cooling signature. Geophys. J. Int. 166, 1384-1397, doi:10.1111/j.1365-246X.2006.03037.x.

Masters, G., Laske, G., Bolton, H., Dziewonski, A.M., 2000. The relative behavior of shear velocity, bulk sound speed, and compressional velocity in the mantle, in: Karato, S., Forte, A., Lieberman, R., Masters, G., Stixrude, L. (Eds.), Earth's Deep Interior: Mineral Physics and Tomography from the Atomic to the Global Scale, Geophysical Monograph, vol. 17. AGU, Washington, DC, pp. 63-87.

McNamara, A.K., Zhong, S., 2004. Thermochemical structures within a spherical mantle: superplumes of piles? J. Geophys. Res. 109, doi:10.1029/2003JB002847.

McNamara, A.K., Zhong, S., 2005. Thermochemical structures beneath Africa and the Pacific Ocean. Nature 437, 1136-1139.

McNutt, M.K. 1998. Superswells. Rev. Geophys, 36, 211-244.

McNutt, M.K., Fischer, K.M., 1987. The South Pacific Superswell, in: Keating, B.H, Fryer, P., Batiza, R., Boehlert, G.W. (Eds.), Seamounts, Islands, and Atolls, Geophys. Monogr. Ser. AGU, Washington, DC, pp. 25-34.

McNutt, M.K., Judge, A.V., 1990. The superswell and mantle dynamics beneath the South Pacific. Science 248, 969-975.

Megnin, C., Romanowicz, B., 2000. The three-dimensional shear velocity structure of the mantle from the inversion of body, surface and higher mode waveforms. Geophys. J. Int. 143, 709-728.

Montelli, R., Nolet, G., Dahlen, F.A., Masters, G., 2006. A catalogue of deep mantle plumes: new results from finite-frequency tomography. Geochem. Geophys. Geosys. 7, doi:10.1029/2006GC001248.

Montelli, R., Nolet, G., Dahlen, F.A., Masters, G., Engdahl, E.R., Hung, S.H., 2004. Finitefrequency tomography reveals a variety of plumes in the mantle. Science 303, 338-343.

Morgan, W.J., 1971. Convection plumes in the lower mantle. Nature 230, 42-43.

Nataf, H.C., 2000. Seismic imaging of mantle plumes. Ann. Rev. Earth Planet. Sci. 28, 391-417.

Obayashi, M., Suetsugu, D., Fukao, Y., 2004. PP-P differential travel time measurement with crustal correction. Geophys. J. Int. 157, 1152-1162.

Olson, P., Nam, I.S., 1986. Formation of seafloor swells by mantle plumes. J. Geophys. Res. 91, 7181-7191.

Paige, C.C., Saunders, M.A., 1982. LSQR: an algorithm for sparse linear equations and sparse least squares. ACM Trans. Math. Softw. 8, 43-71.

Ritsema, J., van Heijst, H.J., Woodhouse, J.H., 1999. Complex shear wave velocity structure imaged beneath Africa and Iceland. Science 286 (5446), 1925-1928.

Suetsugu, D., Shiobara, H., Sugioka, H., Fukao, Y., Kanazawa, T., 2007. Topography of the mantle discontinuities beneath the South Pacific Superswell as inferred from broadband waveforms on seafloor. Phys. Earth Planet. Int. 160, 310-318.

Suetsugu, D., Sugioka, H., Isse, T., Fukao, Y., Shiobara, H., Kanazawa, T., Barruol, G., Schindele, F., Reymond, D., Bonneville, A., Debayle, E., 2005. Probing South Pacific mantle plumes with ocean bottom seismographs. EOS Trans. Am. Geophys. Union 86, 429-435.

Tackley, P.J., 2002. Strong heterogeneity caused by deep mantle layering. Geochem. Geophys. Geosys. 3, doi:10.1029/2001GC000167.

VanDecar, J.C., Crosson, R.S., 1990. Determination of teleseismic relative phase arrival times using multi-channel cross-correlation and least squares. Bull. Seism. Soc. Am. 80, 150-169.

Wessel, P., Smith, W.H.F., 1998. New improved version of generic mapping tools released. EOS Trans. Am. Geophys. Union 79, 579.

Wolfe, C.J., Solomon, S.C., Silver, P.G., VanDecar, J.C., Russo, R.M., 2002. Inversion of body-wave delay times for mantle structure beneath the Hawaiian Islands: results from the PELENET experiment. Earth Planet. Sci. Lett. 198 (1-2), 129-145.

Zhao, D., 2001. Seismic structure and origin of hotspots and mantle plumes. Earth Planet. Sci. Lett. 192 (3), 251-265.

Zhao, D., 2004. Global tomographic images of mantle plumes and subducting slabs: insight into deep Earth dynamics. Phys. Earth Planet. Inter. 146 (1-2), 334.

Zhao, D., Hasegawa, A., Horiuchi, S., 1992. Tomographic imaging of $P$ and $S$ wave velocity structure beneath northeastern Japan. J. Geophys. Res. 97, 19909-19928.

Zhao, D., Lei, J.S., 2004. Seismic ray path variations in a 3D global velocity model. Phys. Earth Planet. Int. 141, 153-166. 